\title{
Current status and implications of microRNAs in ovarian cancer diagnosis and therapy
}

\author{
Mohd Saif Zaman ${ }^{1}$, Diane M Maher ${ }^{1}$, Sheema Khan ${ }^{1}$, Meena Jaggi ${ }^{1,2,3}$ and Subhash C Chauhan ${ }^{1,2,3^{*}}$
}

\begin{abstract}
Ovarian cancer is the fifth most common cancer among women and causes more deaths than any other type of female reproductive cancer. Currently, treatment of ovarian cancer is based on the combination of surgery and chemotherapy. While recurrent ovarian cancer responds to additional chemotherapy treatments, the progression-free interval becomes shorter after each cycle, as chemo-resistance increases until the disease becomes incurable. There is, therefore, a strong need for prognostic and predictive markers to help optimize and personalize treatment in order to improve the outcome of ovarian cancer. An increasing number of studies indicate an essential role for microRNAs in ovarian cancer progression and chemo-resistance. MicroRNAs (miRNAs) are small endogenous non-coding RNAs ( 22bp) which are frequently dysregulated in cancer. Typically, miRNAs are involved in crucial biological processes, including development, differentiation, apoptosis and proliferation. Two families of miRNAs, miR-200 and let-7, are frequently dysregulated in ovarian cancer and have been associated with poor prognosis. Both have been implicated in the regulation of epithelial-to-mesenchymal transition, a cellular transition associated with tumor aggressiveness, tumor invasion and chemo-resistance. Moreover, miRNAs also have possible implications for improving cancer diagnosis; for example miR-200 family, let-7 family, miR-21 and miR-214 may be useful in diagnostic tests to help detect ovarian cancer at an early stage. Additionally, the use of multiple target O-modified antagomirs (MTG-AMO) to inhibit oncogenic miRNAs and miRNA replacement therapy for tumor suppressor miRNAs are essential tools for miRNA based cancer therapeutics. In this review we describe the current status of the role miRNAs play in ovarian cancer and focus on the possibilities of microRNA-based therapies and the use of microRNAs as diagnostic tools.
\end{abstract}

Keywords: Ovarian cancer, miRNAs, Chemoresistance, Diagnosis, Prognosis, Therapy, miR-200, Let-7

\section{Introduction}

Epithelial ovarian cancer (referred to as ovarian cancer in this review) is the fifth most common cancer among women and causes more deaths than any other type of female reproductive cancer [1]. Signs and symptoms of ovarian cancer are frequently absent or ambiguous early on and due to a lack of early detection strategies most $(>60 \%)$ patients are diagnosed with advanced-stage disease. The five year survival rate is less than $30 \%$ for these advanced-stage patients and, despite advances in chemotherapy, survival rates have only modestly improved over

\footnotetext{
* Correspondence: subhash.chauhan@sanfordhealth.org

'Cancer Biology Research Center, Sanford Research/USD, 2301 East 60th Street North, Sioux Falls SD 57104, USA

${ }^{2}$ Department of Obstetrics and Gynecology, Sanford School of Medicine, The University of South Dakota, 2301 East 60th Street North, Sioux Falls SD 57105, USA

Full list of author information is available at the end of the article
}

the past 40 years [1-3]. Pathologically, ovarian cancer is a heterogeneous disease comprised of serous, mucinous, clear cell, and endometrioid subtypes. Serous tumors are the most common subtype. Each subtype is associated with diverse genetic risk factors and molecular events during oncogenesis and is characterized by distinct mRNA expression profiles. It has been observed that subtypes respond differently to chemotherapy. The response rate of clear cell carcinomas (15\%) is very low, whereas the response rate for high-grade serous is $80 \%$, resulting in a lower 5-year survival for clear cell compared with high-grade serous carcinoma in patients with advanced stage tumors $(20 \%$ versus $30 \%)[4,5]$.

The standard treatment for advanced ovarian cancer is surgical tumor debulking (removal of all tumor and metastasis that can be macroscopically detected in the entire abdomen region), followed by platinum-based

\section{Biomed Central}


chemotherapy [6]. Neoadjuvant therapy, the use of chemotherapy or radiation prior to surgery, may be an option for patients with stage IIIC or IV ovarian cancer which typically presents with a large tumor burden and extensive metastases. For these patients optimal debulking may be difficult to achieve, making neoadjuvant therapy an important option [7]; however, there is currently an ongoing debate to clearly identify which patients would benefit from neoadjuvant therapy $[8,9]$.

Chemotherapy in ovarian cancer includes platinumbased drugs, cisplatin or carboplatin coupled with paclitaxel. After first-line treatment with carboplatin and paclitaxel, most patients eventually relapse with a median progression-free survival of 18 months. Recurrent ovarian cancer initially responds to additional chemotherapy; however, the progression-free interval becomes shorter after each cycle as chemo-resistance increases until the disease becomes incurable [10]. A number of molecular mechanisms have been characterized to explain the development of resistance to chemotherapy, such as increased DNA repair activity and defective
DNA damage response [11], increased anti-apoptotic regulator activity [12,13], growth factor receptor deregulation [14] [15] and post-translational modification or aberrant expression of $\beta$-tubulin and other microtubule regulatory proteins [16].

The recently discovered microRNAs (miRNAs) constitute a novel regulatory layer of gene expression and have been implicated in the etiology of various kinds of human cancers. miRNAs are small ( 22bp) endogenous non-coding RNAs and are frequently dysregulated in cancer. Their role is to modulate gene expression mainly by base-pairing to the 3'-UTR (untranslated region) of the target mRNA, eventually causing either translational repression, mRNA cleavage, or destabilization [17]. In ovarian carcinoma the expression of various miRNAs has been found to be dysregulated [18]. Recent reports support a role for miRNAs in the initiation and progression of ovarian carcinoma [19-21] by promoting the expression of proto-oncogenes or by inhibiting the expression of tumor suppressor genes. In this review we focus on the current status of the role miRNAs play in

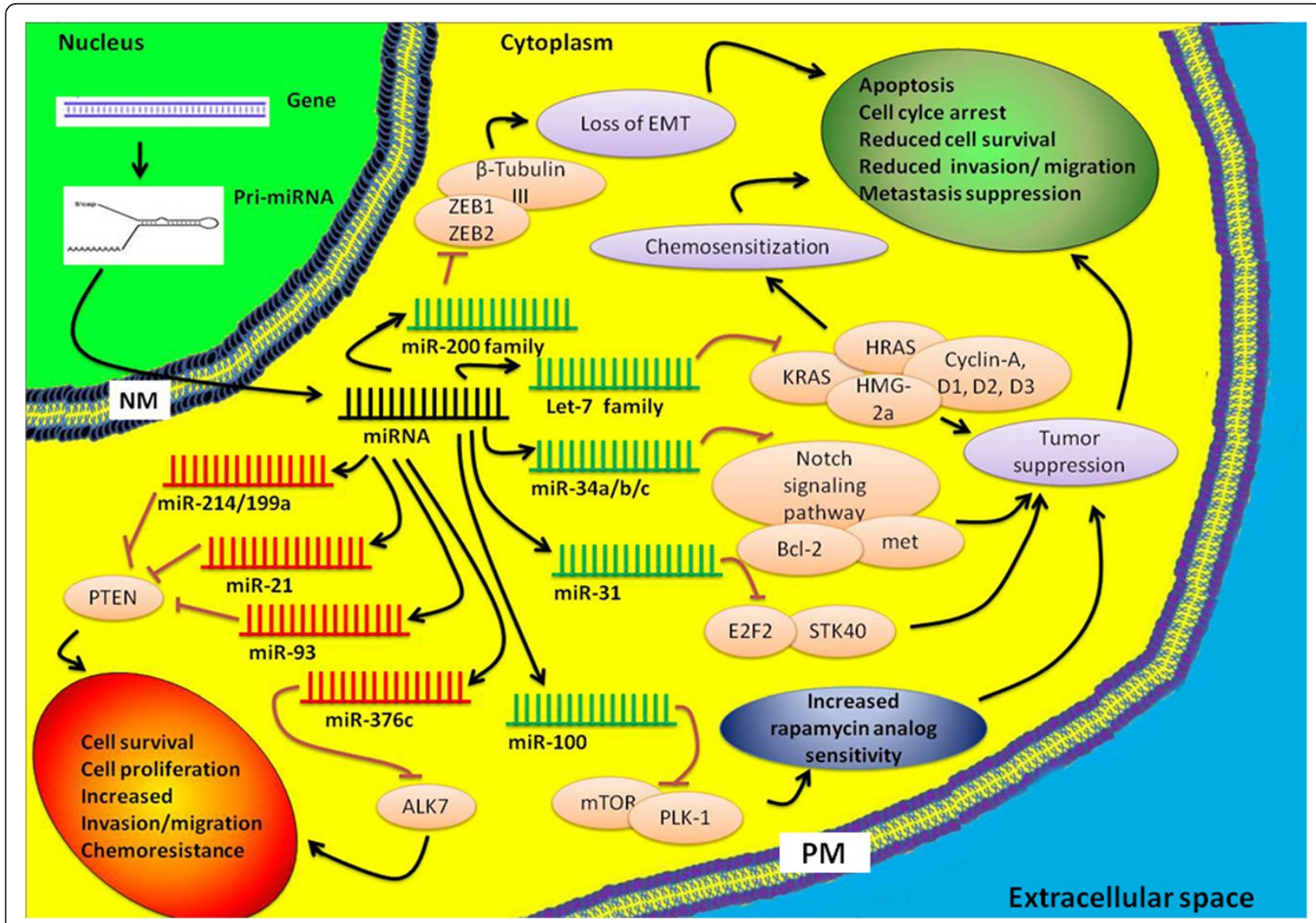

Figure 1 Oncogenic and tumor suppressor miRNAs in ovarian carcinoma. Based on their function miRNAs can be used for diagnostics and therapeutics. Certain miRNAs such as miR-200 family, let-7 family, miR-21, miR-214 and miR-100 have strong diagnostic/prognostic potential in ovarian cancer. Use of antagonists for oncogenic microRNAs and microRNA replacement therapy for tumor suppressor miRNAs are important tools in miRNA based cancer treatment. EMT-Epithelial to Mesenchymal Transition; NM-Nuclear membrane; PM-Plasma membrane. 
ovarian cancer (Figure-1 and Table-1). We also describe their diagnostic / prognostic and therapeutic potential.

\section{miRNAs}

miRNAs were first discovered in 1993 by Lee, Feinbaum and Ambros in the nematode C. elegans [22] and are now known to be present and highly conserved among a wide range of species [23]. Mature miRNAs are derived from precursors called pri-miRNAs, composed of hundreds or thousands of nucleotides [17,24,25]. miRNAs precursor sequences are located in different parts of nuclear DNA and may constitute mono- or policistrone transcriptional units. Pri-miRNAs are transcribed mainly by polymerase RNA II. Subsequently, they are cleaved by the endonuclease Drosha and cofactor DGCR8 into a structure known as precursor miRNA or pre-miRNA. Pre-miRNAs, $\sim 60$ nucleotide stem-loop molecules, are transported from the nucleus to the cytoplasm by Exportin 5 and protein Ran-GTP and further processed by the Dicer enzyme into a $\sim 22$ nucleotide double-stranded microRNA [26]. The double-stranded miRNA assembles into a ribonucleoprotein complex which is known as the RNA induced silencing complex (RISC) [27]. The RISC induces unwinding of the double-stranded molecule into single stranded miRNA, concomitantly degrading the complementary strand. In animals the miRNA-RISC binds to 3' untranslated region (3' UTR) of mRNA, does not require perfect complementarity, and induces inhibition of translation at the initiation or elongation phase
[27]. The mode of inhibition may depend, in part, on the level of complementarity of the miRNAs where perfect or near perfect complementarity favors degradation. The mechanism of 3'UTR mRNA target regulation is complex. Nevertheless, recent studies suggest that it is a two step process in which inhibition of translation is done first, followed by mRNA decay due to deadenylation of the mRNA [28]. The seed sequence is essential for the binding of the miRNA to the mRNA. The seed sequence is a conserved heptamerical sequence which is mostly situated at positions 2-7 from the 5' end of the miRNA, although other factors are also important $[17,29]$. Gu et. al. [30] have suggested that miRNA target sites can also be found in the 5' UTR or even in the coding region of the mRNA. By binding to 5' UTR sequences miRNAs can also activate translation. Thus, inhibition of posttranscriptional mRNA processing is not the only way of regulating miRNA-dependent gene expression [31]. Moreover, as miRNAs do not require perfect complementarity for functional interactions with mRNA targets, a single miRNA can regulate multiple targets and conversely, multiple miRNAs are known to regulate individual mRNAs [32].

\section{miRNAs in cancer}

miRNAs are involved in crucial biological processes, including development, differentiation, apoptosis and proliferation [33]. This is done through imperfect pairing with target messenger RNAs (mRNAs) of protein-coding

Table 1 miRNAs: functions and targets in ovarian cancer

\begin{tabular}{|c|c|c|c|}
\hline microRNAs & Function & Targets & Reference \\
\hline \multirow[t]{2}{*}{ miR-200 family } & Tumor suppressor & ZEB1,ZEB2, $\beta$ tubulin III & {$[31,42,45,47,48,51-59,111,112]$} \\
\hline & (Loss of EMT) & & \\
\hline \multirow[t]{2}{*}{ Let-7 family } & Tumor suppressor & KRAS,HRAS,C-MYC,HMGA-2,CyclinA,D1,D2,D3,CDC25,CDK6 & {$[47,68-81,110,113,116,117]$} \\
\hline & (Chemosensitization) & & \\
\hline \multirow[t]{2}{*}{$\mathrm{miR}-34 \mathrm{a} / \mathrm{b} / \mathrm{c}$} & Tumor suppressor & c-myc,CDK6,Notch-1,MET,E2f3,Bcl2,cyclinD1 & {$[82,119]$} \\
\hline & invasion/migration/pr & & \\
\hline \multirow[t]{2}{*}{ miR-100 } & Tumor suppressor & mTOR, PLK-1 & [83-85] \\
\hline & sensitivity to rapamyc & & \\
\hline \multirow[t]{2}{*}{ miR-31 } & Tumor suppressor & E2F2, STK40 & [86] \\
\hline & (Increased apoptosis) & & \\
\hline \multirow[t]{2}{*}{ miR-214/199a* } & Oncogenic & PTEN & {$[51,87-91,93,112]$} \\
\hline & (Chemoresistance) & & \\
\hline \multirow[t]{2}{*}{ miR-376c } & Oncogenic & ALK7 & {$[21,98]$} \\
\hline & (Chemoresistance) & & \\
\hline \multirow[t]{2}{*}{ miR-93 } & Oncogenic & PTEN & [100-102] \\
\hline & (Chemoresistance) & & \\
\hline $\operatorname{miR}-21$ & Oncogenic & PTEN & {$[47,51,104-107,112]$} \\
\hline
\end{tabular}

miRNAs in ovarian carcinoma can either be oncogenic or tumor suppressor. Tumor suppressor miRNAs suppress oncogenes resulting in either loss of EMT (Epithelial Mesenchymal Transition), chemosensitization or tumor suppression. Whereas, oncogenic miRNAs target tumor suppressor genes leading to chemo resistance and reduced survival. 
genes and the transcriptional or post-transcriptional regulation of their expression [26]. The first reported link between miRNAs and cancer regarded chronic lymphocytic leukemia, wherein miR-15 and miR-16 were found to be deleted or down-regulated in a majority of tumors [34]. Since then, changes in the expression level of miRNAs have subsequently been detected in many types of human tumors [35]. miRNAs have various roles in oncogenesis as they can function either as tumor suppressors (e.g., miR-15a and miR-16-1) or oncogenes (e.g., miR-155 or members of the miR-17-92 cluster). Recent studies on the abnormal expression of miRNAs in cancer have described the following reasons for differential expression: chromosomal rearrangements [36-38], genomic copy number change $[39,40]$, epigenetic modifications [41,42], defects in miRNA biogenesis pathway [43], and regulation by transcription factors [44].

\section{miRNAs in ovarian cancer}

One of the seminal studies done on epithelial ovarian cancer (EOC) and miRNA was done by Zhang et. al. in 2008 [45]. In this study the authors utilized an integrative genomic approach to study miRNA deregulation in human epithelial ovarian cancer. They compared mature miRNA expression profiles in 18 ovarian cancer cell lines and 4 immortalized, non neoplastic cell lines derived from normal ovarian surface epithelium. Thirty five miRNAs were found to be differentially expressed between the two groups of cells. Out of these 35, only 4 were up-regulated, whereas the rest were mostly downregulated in cancer cells as compared to immortalized non-neoplastic cell lines. The 4 up-regulated miRNAs were miR-26b, miR-182, miR-103 and miR-26a. The list of down-regulated miRNAs included prominent tumor suppressors such as let-7d and miR-127. This showed that miRNA expression profiles can distinguish malignant from nonmalignant ovarian surface epithelium. Zhang et. al. went on to analyze 106 primary human ovarian cancer specimens of various stages and grades using miRNA microarrays. They found that all tumor suppressor miRNA alterations were related to downregulation in late stage tumors, which included miR-15a, miR-34a and miR-34b. The authors also observed that
DNA copy number loss and epigenetic silencing are mainly responsible for down-regulation of the miRNAs. In the case of over-expressed miRNAs (oncogenic miRNAs such as miR-182) the chromosomal regions were found to be amplified in a significant number of cancer samples. Additionally, epigenetic alterations reduced the expression of 16 out of 44 miRNAs which were downregulated in late-stage ovarian cancer as the expression of these miRNAs, e.g. miR-34b, was restored by DNA demethylation or histone deacetylase inhibiting agents.

In addition several studies have compared the expression profile of miRNAs in a large number of clinical ovarian cancer samples to normal ovarian tissues, ovarian epithelial cell lines or fallopian tubes [42,46-51]. The following sections provide information regarding miRNAs that are suggested to be involved in the pathobiology of ovarian cancer (Tables 1 and 2).

\section{miRNA-200 family}

The miR-200 family contains miR-200a, miR-200b, miR200c, miR-141 and miR-429 which are arranged in 2 clusters in the human genome. miR-200a, miR-200b and miR-429 are located on chromosome 1, while miR-200c and miR-141 are on chromosome 12 [52]. Iorio et. al. [42] have shown that the miR-200 family is among the most significantly over-expressed miRNAs in epithelial ovarian cancer. The expression of miR-200a and miR200c was found to be up-regulated in three types of ovarian cancer: serous, endometrioid and clear cell. However, miR-200b and miR-141 are up-regulated in endometrioid and serous subtypes. The role of the miR200 family in ovarian carcinoma is complicated. While miR-200 family members are believed to be metastasis suppressants, the majority of studies done on the family relate to over expression in ovarian cancer. However, some studies report that miR-200 family members are either down regulated [48] or even unchanged [45]. These differing results may occur because of the use of different normal controls or the inclusion of ovarian stromal cells which lack miR-200 expression.

Further complicating the potential roles of the miR200 family members, recent studies have implicated the miR-200 family with the regulation of the epithelial to

Table 2 miRNA profile of subtypes of ovarian cancer

\begin{tabular}{lccc}
\hline $\begin{array}{l}\text { Type of ovarian } \\
\text { cancer }\end{array}$ & Up-regulated miRNA & Down-regulated miRNA & References \\
\hline Serous & miR-200a, miR-200b, miR-200c, miR-141, miR-93, miR-21, & let7-b, miR-99a, miR-125b, miR-22, miR- & {$[42,47,51,86,102,106,108,109]$} \\
& miR-519a, miR-214 & 31, miR-34a/b/c & {$[42,51,83,109]$} \\
\hline Clear Cell & miR-519a, miR-182, miR-30a,miR-21, miR-200a, miR-200c & miR-100, miR-22, miR-34a/b/c, miR-214 & {$[109]$} \\
\hline Mucinous & miR-153, miR-485-5p & & {$[42]$} \\
\hline Endometrioid & miR-200a, miR-200b, miR-200c, miR-141 & & \\
\hline
\end{tabular}

Most of the miRNA profiling has been done on the serous and clear cell ovarian carcinoma. miR-200 family stands out as the up-regulated miRNA in most types of ovarian cancer. miR-100 plays a specific role in clear cell ovarian carcinoma. 
mesenchymal transition (EMT). EMT is a process where epithelial tumor cells are stimulated by extracellular cytokines, e.g. TGF $\beta$, or intracellular molecules such as oncogenic Ras, to change their epithelial characteristics into a mesenchymal phenotype with increased migratory and invasive capabilities. EMT is induced by a group of transcriptional repressors, such as Snail, Slug, TWIST, Id2, ZEB1 and ZEB2. The protein levels of these repressors increase during EMT, resulting in the downregulation of genes such as E-cadherin which are responsible for the epithelial identity of the cells [53]. The E-cadherin molecules mediate cell-cell adhesion. Park et. al. [54] have shown a positive correlation in the expression of E-cadherin with the expression of miR200c in ovarian cancer tissues. The miR-200 family members have also been shown to suppress the expression of ZEB1 and ZEB2, thereby suppressing EMT. Over expression of miR-200 a/b/c and/or miR-141 down regulates ZEB1/2 levels, and leads to higher levels of E-cadherin and an epithelial phenotype. On the contrary, ZEB1/2 can inhibit the expression of miR-200 family members by binding to the promoter of both miR-200 clusters thereby blocking transcription. The mechanistic explanation of the above process can be summarized as follows: activation of a trigger such as TGF- $\beta$ or PDGF-D [52], leads to increased levels of ZEB1/2, decreased expression of miR-200 and the induction of EMT [31,54-57]. The miR-200 family might be down regulated when cancer cells acquire invasive properties and then become up-regulated when the cells undergo mesenchymal to epithelial transition during the process of re-epithelialization, which is evident from the positive correlation of miR-200 and Ecadherin expressions [58].

In a recent study, Leskela et. al. [59] demonstrated the role of the miR-200 family members in controlling $\beta$ tubulin III expression and its association with paclitaxelbased treatment response and progression-free survival in ovarian cancer patients. Previous studies demonstrated that high tumoral $\beta$-tubulin III expression has been associated with decreased survival with non-small cell lung cancer [60,61], breast [62], head and neck [63] and ovarian cancer [64]. Moreover, a number of studies have also shown that high expression of $\beta$-tubulin III is associated with worse treatment response in ovarian cancer [65-67]. Leskela et. al. found that tumors with high levels of $\beta$-tubulin III protein have significantly decreased miR-200 expression. They observed the strongest associations with miR-141, miR-429 and miR-200c. miR-200c expression was statistically significantly associated with response to treatment as patients who did not achieve a complete clinical response had lower levels of miR-200c as compared to those showing a complete response. Low expression of miR-200c was also associated with recurrence of ovarian cancer. Moreover, miR-429 expression was found to be significantly associated with recurrence-free survival and overall survival of the patients [59].

\section{Let-7 family}

The let-7 (lethal-7) family in humans consists of $13 \mathrm{miR}-$ NAs located on nine different chromosomes $[68,69]$. In multiple human cancers expression of the let-7 family is significantly reduced. Low let-7 expression has been found to be associated with poor survival of cancer patients [70,71]. Let-7 suppresses multiple ovarian cancer oncogenes, which includes KRAS, HRAS[72], $c-M Y C$ [72] and HMGA-2 [73]. Moreover, it also inhibits cell cycle regulators such as CDC25, CDK6 as well as Cyclin A, D1, D2 and D3 [74,75]. The mechanism of downregulation for let-7 miRNAs is through copy-number alterations [76]. The genomic locus containing let-7a-3/ let-7b was deleted in $44 \%$ of ovarian cancer samples studied. Restoration of let-7b expression significantly reduced ovarian tumor growth both in vitro and in vivo.

Additionally, recent studies have shown a correlation between loss of let-7 and resistance to either chemotherapeutic drugs or radiation [71,77-79]. Using a drug resistant ovarian cancer cell line, Boyerinas et. al. [80] demonstrated that drug sensitivity to taxanes is increased upon over expression of let-7g as it inhibits IMP-1, an RNA binding protein which stabilizes the mRNA of a number of target genes, including, MDR1 (multidrug resistance-1). MDR1 is a member of the adenosine triphosphate binding cassette transporters (ABC transporter family) which pump drugs across the cell membrane to the extracellular space. Therefore, the expression of let-7g resulted in a decrease in MDR1 and sensitized the cells to Taxane treatment.

On the other hand, Lu et. al. [81] observed that ovarian cancer patients responding to a regimen of platinum and paclitaxel had significantly lower let-7a expression than those who did not respond to treatment. Moreover, survival data indicated that patients with high let-7a survived better when they were treated with platinum only (no paclitaxel) as compared to those having low expression of let-7a. The authors conclude that miRNA-let-7a expression can be a potential marker for selection of chemotherapeutic agents in ovarian cancer treatment.

\section{miRNA-34 a/b/c}

Quantitative-RT PCR and in-situ hybridization in a panel of 83 human ovarian cancer samples showed a significant decrease in miR-34a/b/c expression. The decrease was also correlated with the p53 status as p53 regulates the expression of miR-34 family members by promoter methylation and copy number alterations [82]. Over-expression of miR-34 family members reduced 
migration, invasion and cellular proliferation in ovarian cancer cell lines, providing evidence that the loss of miR-34 family members may be involved in the pathobiology of ovarian cancer.

\section{miRNA-100}

miR-100 is a tumor suppressor which has been found to be down-regulated in most of the ovarian cancer cell lines, especially clear cell ovarian carcinoma cell lines and ovarian cancer tissues [83,84]. miR-100 represses mTOR (mammalian target of rapamycin) signaling and increases sensitivity to the cancer drug everolimus (rapamycin analog RAD001) in cell lines derived from clear cell carcinomas. mTOR is a serine/threonine kinase and is a downstream effector of the Akt signaling pathway. mTOR has also been shown to be a possible therapeutic target in both cisplatin-sensitive and cisplatin-resistant clear cell ovarian carcinoma [85]. Low miR-100 expression was associated with shorter overall patient survival and advanced stage ovarian cancer. Moreover, its expression has been shown to be an independent predictor of overall survival in ovarian cancer patients. miR-100 also inhibits the expression of the proto-oncogene PLK1 (Polo-like kinase-1) in ovarian cancer [84].

\section{miRNA-31}

miR-31 is under-expressed in both serous ovarian cancer cell lines and tissues [86]. miRNA-31 inhibits the expression of cell cycle regulators such as E2F2 and STK40, a repressor of p53 mediated transcription, and acts as a tumor suppressor in ovarian cancer. Over expression of miR-31 in ovarian cancer cell lines having non functional p53 pathways lead to decreased proliferation and increased caspase-mediated apoptosis, whereas, over expression of miR-31 had no effect on ovarian cancer cells having wild-type p53 [86]. Thus, miRNA-31 might have therapeutic roles in the case of cancers having p53 mutations.

\section{miRNA-214/199a*}

Up-regulation of miR-214 has been detected in various human malignancies, including pancreatic, prostate, gastric, breast and ovarian cancers as well as malignant melanoma [51,87-90]. miR-214 has extensive roles in chemo-resistance, tumor progression and metastasis [51,87,88,91]. Yang et. al. [51] have shown that miR-214 induces cell survival and cisplatin resistance by targeting PTEN. miRNA microarrays show the aberrant regulation of 36 miRNAs between normal ovarian cells and epithelial ovarian tumors [51]. miR-199a*, miR-214, miR-200a and miR-100 were most highly differentially expressed. miR-199a* and miR-214 were found to be up-regulated in 53 and $56 \%$ of the tumor tissues, respectively. miR214 knockdown was found to abrogate cisplatin resistance in cisplatin-resistant cell line A2780CP, whereas exogenous expression of miR-214 renders cisplatin-sensitive cell line A2780S and OV119 cells resistant to cisplatin induced apoptosis. miR-214 activates the Akt pathway by targeting PTEN, which normally negatively regulates Akt. Constitutive activation of Akt leads to chemo-resistance in different types of tumors including ovarian cancer [92]. Thus, miR-214 possibly plays an important role in cisplatin resistance by targeting the PTEN/Akt pathway. miR-199a and miR-214 have been implicated in the process of differentiation of ovarian cancer stem cells (CSCs) into mature ovarian cancer cells [93]. Twist 1, a transcription factor belonging to basic helix-loop-helix proteins has been shown to regulate the expression of both miR-199a and miR-214 which are part of the human Dnm3os gene. Twist 1 is involved in the differentiation of multiple cell lineages, including muscle, cartilage and osteogenic cells [94-97]. Twist 1 levels increase during the differentiation process leading to an increase in miR-199a and miR-214, a decrease in IKK $\beta$ expression (target of miR-199a), and a decrease in PTEN expression (target of miR-214). This eventually results in an increase in the pAkt activity leading to the process of differentiation.

\section{miRNA-376c}

miRNA-376c was earlier known as miR-368 and was found to be over expressed in a subset of acute myeloid leukemia [98]. Ye et. al. have shown that miR-376c promotes cell proliferation, survival and spheroid formation in ovarian cancer cells [21]. This is done by suppressing activin receptor-like kinase 7 (ALK7) and its ligand Nodal, which together are able to induce apoptosis in human epithelial ovarian cancer cells. A previous study had demonstrated that the Nodal-ALK7 pathway might be involved in chemosensitivity [99]. miR-376c over expression significantly reduced the effect of cisplatin. Moreover, miR-376c and siRNA inhibitors of Nodal and ALK7 also blocked the effect of carboplatin. Chemosensitive and chemoresistant ovarian tumors showed a differential expression of ALK7 and miR376c. Immuno-histochemical staining was used to stain tumors with ALK7 and miR-376c was detected using real-time PCR, in patients showing a complete response (CR) and those who had an incomplete response (IR). Patients showing CR showed significant ALK7 staining, whereas the staining intensity was very weak in patients with IR. Additionally, the miR-376c expression level was inversely related to ALK7 in both cases [21].

\section{miRNA-93}

miRNA-93 is part of the miR-106b-25 cluster [100]. It has been shown to promote tumor growth and angiogenesis by targeting integrin- $\beta 8$ [101]. In ovarian cancer 
it is up-regulated in cisplatin-resistant ovarian cancer cells [102]. It regulates cisplatin chemosensitivity in cisplatin resistant ovarian cancer cells OVCAR3 and SKOV3 by targeting the phosphatase PTEN. Overexpression of miR-93 in both these cells increased the ratio of phosphorylated Akt/over the total Akt (pAkt/ total Akt). Phospho rylated-Akt has been shown to play an important role in multiple drug resistance including cisplatin $[92,103]$.

\section{miRNA-21}

miR-21 is aberrantly expressed and functions as an oncogenic miRNA in many tumors including ovarian cancer $[51,104,105]$. In ovarian cancer cells it promotes cell proliferation, invasion and migration through targeting PTEN [106]. miR-21 also has a role in resistance to hypoxic conditions which inhibit tumor growth [107]. Protein kinase Akt2 induces miR-21 expression under oxygen deprivation leading to suppression of tumor suppressor proteins PTEN, PDCD4 and Sprouty 1 (targets of miR-21). This results in resistance to hypoxia [107].

miRNA expression profiles of subtypes of ovarian cancer In addition to the miRNAs discussed above, a number of studies have profiled the miRNA expression of specific subtypes of ovarian cancer. Nam et. al., used a customized miRNA microarray of 314 human miRNAs to analyze the miRNA expression profiles of serous ovarian cancer tissues as compared to normal ovarian tissues [47]. They found differential expression of 23 miRNAs. miR-21 was most frequently up-regulated and miR-125b was most frequently down- regulated (Table-2). Northern blot analysis confirmed the up-regulation of miR200c, miR-93 and miR-141 and the down-regulation of let-7b, miR-99a and miR-125b. In a separate study, Li et. al. have shown a negative correlation between miR-22 expression and the metastatic potential in serous ovarian cancer cell lines [108]. Additionally, miR-519a was found to be significantly up-regulated in serous and clear cell carcinomas as compared to the mucinous subtype in tissue samples [109]. Higher expression of miR-519a in late stage serous carcinoma showed positive correlation with poor progression-free survival. miR-153 and miR-485-5p were found to be up-regulated in mucinous ovarian carcinoma. The down-regulation of miR-153 and miR-485$5 p$ showed significant correlation with advanced clinical stage FIGO (International Federation of Gynecology and Obstetrics) grade 3 and miR-519a was found to be high in clinical stages III and IV (advanced clinical stages) as compared to stages I and II (early clinical stages) [109]. As mentioned above miR-100 has been shown to be down-regulated in clear cell ovarian carcinoma cell lines and its over-expression in them inhibited mTOR signaling and enhanced sensitivity to rapamycin analog
RAD001 (everolimus) [83] (Table-2). In the same study the authors show the down-regulation of miR-22 and the up-regulation of miR-182 and miR-30a in clear cell ovarian carcinoma cell lines. Over-expression of miR-22 and knockdown of miR-182 could alter the global gene expression pattern of clear cell ovarian cell lines towards a normal state [83].

\section{miRNAs in ovarian cancer diagnostics / prognostics}

Previous studies in ovarian carcinoma have shown that miRNAs can be used in its diagnosis as well as prognosis. Lu et. al. [110] demonstrated that patients having low let-7a-3 methylation had overall worse survival than those with high methylation. The miRNA-200 family plays an important role in ovarian cancer and it has been shown that the miR-200 family cluster, which includes miR-200a, miR-200b and miR-429, can predict poor survival when they are expressed at low levels [111]. Yang et. al. [51] showed that miR-214, miR-199* and miR200a were associated with high-grade and late stage tumors. In an interesting ovarian cancer study [112] the authors profiled miRNA signatures from tumor-derived exosomes. Levels of 8 miRNAs, which were previously shown to have diagnostic potential (miR-21, 141, 200a, 200c, 200b, 203, 205 and miR-214), were compared in exosomes isolated from serum specimens of women with benign disease and various stages of cancer. The 8 miRNAs had similar expressions between cellular and exosomal miRNAs, with no detection of exosomal miRNAs in control samples. The profile of exosomal miRNAs from ovarian cancer patients was distinctly different from patients with benign disease. HMGA2/let7 ratio has also been used for prognostic studies [113]. High-mobility group AT-hook 2 (HMGA2), an early embryonic gene is a target of miRNAs let-7a, let-7c and let-7g. Higher HMGA2/let-7 ratio exhibited decreased 5 -year progression-free survival $(<10 \%)$ as compared to a lower ratio $(\sim 40 \%)$.

\section{Potential role of miRNAs in ovarian cancer therapeutics} miRNA therapeutics in ovarian cancer can take different forms. Oncogenic miRNAs can be inhibited by using antisense oligonucleotides, antagomirs, sponges or locked nucleic acid (LNA) constructs [114]. Cancer cells have dysregulation in several miRNAs at the same time and targeting a single miRNA is not sufficient for treatment. Multiple-target anti-miRNA antisense oligodeoxyribonucleotide-MTG-AMO (Multiple target-O-modified antagomirs) are used to inhibit multiple miRNAs at the same time [115]. The expression of tumor suppressor miRNAs can be restored by miRNA replacement therapy. Several miRNAs have been used for this purpose. Use of let-7 miRNA mimetics is a potential tool as intra-tumoral delivery 
of let-7b has been shown to decrease the tumor burden in lung tumors $[116,117]$. The miR-143-145 cluster has been shown to be frequently deleted in cancer. miR-143 and 145, delivered intravenously to subcutaneous and orthotopic xenografts downregulated the oncogenes RREB1 and KRAS [118]. One of the more beneficial miRNA therapies is miR-34 replacement therapy. P53 protein is known to enhance miR34 expression and it is mutated in many cancers [119]. The intra-tumoral delivery of miR-34 mimics impaired tumorigenesis on a xenograft model of nonsmall cell lung cancer, and systemic delivery of miR34 reduced tumor growth of KrasLSL-G12D ${ }^{+}$mice $[117,120]$. Certain small molecule compounds like enoxacin have been shown to restore downregulated miRNAs to a normal miRNA level or expression pattern without affecting normal cells and with no toxicity in in vivo models [121,122].

miRNAs can also be used to sensitize tumors to chemotherapy. The efflux of anticancer drugs by $A B C$ transporters is one of the main reasons resistance to chemotherapy drugs develops. miR-9 has been shown to negatively regulate SOX2 which induces the expression of $\mathrm{ABC}$ transporters $\mathrm{ABCC} 3$ and $\mathrm{ABCC} 6$ [123]. Resistance to tamoxifen is restored by the over expression of miR-15 and miR-16. miR-15 and 16 suppress the antiapoptotic molecule BCL-2 and sensitize the cells to tamoxifen [124]. Similarly, use of antagomirs against miR-21 was found to sensitize cultured cells to the chemotherapeutic agent 5-Fluorouracil (5-FU) [125].

One of the greatest challenges in RNAi therapy continues to be the delivery method of the therapeutic siRNA or miRNA to the target cells. Future focus should be aimed at addressing these issues by engineering an efficient delivery system by use of radiolabeled, tumor specific antibody conjugated nanoformulations to deliver miRNA to the ovarian tumor site. It is very important to formulate an effective delivery method, such as nanotechnology-based delivery approach for microRNA for therapy with the help of strategic image-guided systemic delivery to the tumor. This will be a major contribution in the field of cancer therapeutics and will help overcome challenges in miRNA delivery. The goal of this novel therapeutic approach is to effectively encourage reprogramming of miRNA networks in cancer cells which may lead to a clinically translatable miRNA-based therapy to benefit ovarian cancer patients.

\section{Conclusions}

In spite of all the above advances there is still a long way to go to understand and apply miRNA therapeutics in cancer and ovarian cancer in particular. Identification of unique patterns of deregulated miRNA expression in ovarian cancer provides valuable information that may: serve as molecular biomarkers for tumor diagnosis; identify low and high risk populations of patients, disease prognosis and prevention of cancer, and predict therapeutic responses. One of the areas of improvement in miRNA therapy has been to reduce or eliminate offtarget or non-specific effects. This regulatory network is complex because of the fact that a single miRNA can have multiple targets and several miRNAs can have a single target. Therefore, careful designing of therapeutic strategies is needed to overcome these technical issues. Moreover, the identification of new strategies is required to enhance the potency and stability of therapeutic vectors and the specificity of their delivery to tissues. We hope that with increased understanding of the role of miRNAs in cancer development and by designing more efficient miRNA-modulating molecules, miRNA mediated cancer therapy will give a new impetus to the cure for cancer including ovarian cancer.

\section{Abbreviations}

miRNA: MicroRNA; EMT: Epithelial to mesenchymal transition; RISC: RNAinduced silencing complex; UTR: Untranslated region; EOC: Epithelial ovarian cancer/ovarian cancer.

\section{Competing interests}

The authors declare that there are no financial and non financial competing interests.

\section{Authors' contributions}

MSZ designed and drafted the manuscript; MJ, DMM and SK were involved in the critical revision of the manuscript; SCC gave final approval of the version to be published. All authors read and approved the final manuscript

\section{Acknowledgements}

The authors thank Cathy Christopherson for editorial assistance and Dr. Mohammed Sikander for preparing the figure. This work was partially supported by grants to SCC from Governor's Cancer 2010, the National Institutes of Health Research Project Grant Program (RO1) (CA142736), and (UO1) (CA162106A) and the Centers of Biomedical Research Excellence (P20 RR024219).

\section{Author details}

${ }^{1}$ Cancer Biology Research Center, Sanford Research/USD, 2301 East 60th Street North, Sioux Falls SD 57104, USA. ${ }^{2}$ Department of Obstetrics and Gynecology, Sanford School of Medicine, The University of South Dakota, 2301 East 60th Street North, Sioux Falls SD 57105, USA. ${ }^{3}$ Basic Biomedical Science Division, Sanford School of Medicine, The University of South Dakota, 2301 East 60th Street North, Sioux Falls SD 57105, USA.

Received: 20 October 2012 Accepted: 6 December 2012 Published: 13 December 2012

\section{References}

1. Siegel R, Naishadham D, Jemal A: Cancer statistics, 2012. CA Cancer J Clin 2012, 62(1):10-29.

2. Wright JD, Shah M, Mathew L, Burke WM, Culhane J, Goldman N, Schiff PB, Herzog TJ: Fertility preservation in young women with epithelial ovarian cancer. Cancer 2009, 115(18):4118-4126.

3. Fung-Kee-Fung M, Oliver T, Elit L, Oza A, Hirte HW, Bryson P: Optimal chemotherapy treatment for women with recurrent ovarian cancer. Curr Oncol 2007, 14(5):195-208.

4. Takano M, Kikuchi Y, Yaegashi N, Kuzuya K, Ueki M, Tsuda H, Suzuki M, Kigawa J, Takeuchi S, Moriya T, et al: Clear cell carcinoma of the ovary: a 
retrospective multicentre experience of 254 patients with complete surgical staging. Br J Cancer 2006, 94(10):1369-1374.

5. du Bois A, Luck HJ, Meier W, Adams HP, Mobus V, Costa S, Bauknecht T, Richter B, Warm M, Schroder W, et al: A randomized clinical trial of cisplatin/paclitaxel versus carboplatin/paclitaxel as first-line treatment of ovarian cancer. J Natl Cancer Inst 2003, 95(17):1320-1329.

6. Shih le M, Kurman RJ: Ovarian tumorigenesis: a proposed model based on morphological and molecular genetic analysis. Am J Pathol 2004 164(5):1511-1518.

7. Morgan RJ, Alvarez RD, Armstrong DK, Burger RA, Castells M, Chen LM, Copeland L, Crispens MA, Gershenson D, Gray H, et al: Ovarian Cancer, Version 3.2012. J Natl Compr Canc Netw 2012, 10(11):1339-1349.

8. Vergote I, du Bois A, Amant F, Heitz F, Leunen K, Harter P: Neoadjuvant chemotherapy in advanced ovarian cancer: On what do we agree and disagree. Gynecol Oncol 2012, Sep 21 (Epub ahead of print).

9. Gonzalez-Martin A, Chiva L: Emerging Concerns When Evidence-Based Medicine Is Translated into Real Life: The Case of Neoadjuvant Chemotherapy in Ovarian Cancer. Curr Oncol Rep 2012, Oct 9 (epub ahead of print).

10. Cannistra SA: Cancer of the ovary. N Engl J Med 2004, 351(24):2519-2529.

11. Rabik CA, Dolan ME: Molecular mechanisms of resistance and toxicity associated with platinating agents. Cancer Treat Rev 2007, 33(1):9-23.

12. Fraser M, Bai T, Tsang BK: Akt promotes cisplatin resistance in human ovarian cancer cells through inhibition of p53 phosphorylation and nuclear function. Int J Cancer 2008, 122(3):534-546.

13. Behbakht K, Qamar L, Aldridge CS, Coletta RD, Davidson SA, Thorburn A, Ford HL: Six 1 overexpression in ovarian carcinoma causes resistance to TRAIL-mediated apoptosis and is associated with poor survival. Cancer Res 2007, 67(7):3036-3042.

14. Duan Z, Foster R, Bell DA, Mahoney J, Wolak K, Vaidya A, Hampel C, Lee H, Seiden MV: Signal transducers and activators of transcription 3 pathway activation in drug-resistant ovarian cancer. Clin Cancer Res 2006, 12(17):5055-5063.

15. Gan Y, Wientjes MG, Au JL: Expression of basic fibroblast growth factor correlates with resistance to paclitaxel in human patient tumors. Pharm Res 2006, 23(6):1324-1331.

16. Ferlini C, Raspaglio G, Cicchillitti L, Mozzetti S, Prislei S, Bartollino S, Scambia G: Looking at drug resistance mechanisms for microtubule interacting drugs: does TUBB3 work? Curr Cancer Drug Targets 2007, 7(8):704-712.

17. Bartel DP: MicroRNAs: genomics, biogenesis, mechanism, and function. Cell 2004, 116(2):281-297.

18. Bartels $\mathrm{CL}$, Tsongalis GJ: MicroRNAs: novel biomarkers for human cancer. Clin Chem 2009, 55(4):623-631.

19. Sorrentino A, Liu CG, Addario A, Peschle C, Scambia G, Ferlini C: Role of microRNAs in drug-resistant ovarian cancer cells. Gynecol Oncol 2008, 111(3):478-486.

20. Marchini S, Fruscio R, Clivio L, Beltrame L, Porcu L, Nerini IF, Cavalieri D, Chiorino G, Cattoretti G, Mangioni C, et al: Resistance to platinum-based chemotherapy is associated with epithelial to mesenchymal transition in epithelial ovarian cancer. Eur J Cancer 2012, Aug 13, (Epub ahead of print).

21. Ye G, Fu G, Cui S, Zhao S, Bernaudo S, Bai Y, Ding Y, Zhang Y, Yang BB, Peng C: MicroRNA 376c enhances ovarian cancer cell survival by targeting activin receptor-like kinase 7: implications for chemoresistance. J Cell Sci 2011, 124(Pt 3):359-368.

22. Lee $R C$, Feinbaum RL, Ambros V: The $C$. elegans heterochronic gene lin- 4 encodes small RNAs with antisense complementarity to lin-14. Cell 1993 75(5):843-854

23. Wheeler BM, Heimberg AM, Moy VN, Sperling EA, Holstein TW, Heber S, Peterson KJ: The deep evolution of metazoan microRNAs. Evol Dev 2009, 11(1):50-68.

24. Ambros V: The functions of animal microRNAs. Nature 2004, 431(7006):350-355.

25. Cai $X$, Hagedorn $\mathrm{CH}$, Cullen BR: Human microRNAs are processed from capped, polyadenylated transcripts that can also function as mRNAs. RNA 2004, 10(12):1957-1966.

26. Kim YK, Kim VN: Processing of intronic microRNAs. EMBO J 2007, 26(3):775-783

27. Pratt AJ, MacRae IJ: The RNA-induced silencing complex: a versatile gene-silencing machine. J Biol Chem 2009, 284(27):17897-17901.

28. Fabian MR, Mathonnet G, Sundermeier T, Mathys H, Zipprich JT, Svitkin YV, Rivas F, Jinek M, Wohlschlegel J, Doudna JA, et al: Mammalian miRNA RISC recruits CAF1 and PABP to affect PABP-dependent deadenylation. Mol Cell 2009, 35(6):868-880.

29. Grimson A, Farh KK, Johnston WK, Garrett-Engele P, Lim LP, Bartel DP: MicroRNA targeting specificity in mammals: determinants beyond seed pairing. Mol Cell 2007, 27(1):91-105

30. Gu S, Jin L, Zhang F, Sarnow P, Kay MA: Biological basis for restriction of microRNA targets to the $3^{\prime}$ untranslated region in mammalian mRNAs. Nat Struct Mol Biol 2009, 16(2):144-150.

31. Vasudevan S, Tong Y, Steitz JA: Cell-cycle control of microRNA-mediated translation regulation. Cell Cycle 2008, 7(11):1545-1549.

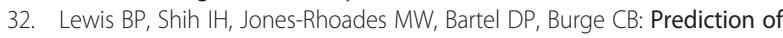
mammalian microRNA targets. Cell 2003, 115(7):787-798.

33. Flynt AS, Lai EC: Biological principles of microRNA-mediated regulation: shared themes amid diversity. Nat Rev Genet 2008, 9(11):831-842.

34. Calin GA, Dumitru CD, Shimizu M, Bichi R, Zupo S, Noch E, Aldler H, Rattan S, Keating M, Rai K, et al: Frequent deletions and down-regulation of micro- RNA genes miR15 and miR16 at 13q14 in chronic lymphocytic leukemia. Proc Natl Acad Sci U S A 2002, 99(24):15524-15529.

35. Zhang W, Dahlberg JE, Tam W: MicroRNAs in tumorigenesis: a primer. Am J Pathol 2007, 171(3):728-738.

36. Calin GA, Ferracin M, Cimmino A, Di Leva G, Shimizu M, Wojcik SE, lorio MV Visone R, Sever NI, Fabbri M, et al: A MicroRNA signature associated with prognosis and progression in chronic lymphocytic leukemia. N Engl J Med 2005, 353(17):1793-1801

37. Calin GA, Croce CM: Chromosomal rearrangements and microRNAs: a new cancer link with clinical implications. J Clin Invest 2007, 117(8):2059-2066

38. Tagawa $\mathrm{H}$, Seto M: A microRNA cluster as a target of genomic amplification in malignant lymphoma. Leukemia 2005, 19(11):2013-2016.

39. Calin GA, Sevignani C, Dumitru CD, Hyslop T, Noch E, Yendamuri S, Shimizu M, Rattan S, Bullrich F, Negrini M, et al: Human microRNA genes are frequently located at fragile sites and genomic regions involved in cancers. Proc Natl Acad Sci U S A 2004, 101(9):2999-3004.

40. Giannakakis A, Sandaltzopoulos R, Greshock J, Liang S, Huang J, Hasegawa K, Li C, O'Brien-Jenkins A, Katsaros D, Weber BL, et al: miR-210 links hypoxia with cell cycle regulation and is deleted in human epithelial ovarian cancer. Cancer Biol Ther 2008, 7:255-264.

41. Saito $Y$, Liang G, Egger G, Friedman JM, Chuang JC, Coetzee GA, Jones PA: Specific activation of microRNA-127 with downregulation of the protooncogene BCL6 by chromatin-modifying drugs in human cancer cells. Cancer Cell 2006, 9(6):435-443.

42. Iorio MV, Visone R, Di Leva G, Donati V, Petrocca F, Casalini P, Taccioli C, Volinia S, Liu CG, Alder H, et al: MicroRNA signatures in human ovarian cancer. Cancer Res 2007, 67(18):8699-8707.

43. Kumar MS, Lu J, Mercer KL, Golub TR, Jacks T: Impaired microRNA processing enhances cellular transformation and tumorigenesis. Nat Genet 2007, 39(5):673-677.

44. He L, He X, Lim LP, de Stanchina E, Xuan Z, Liang Y, Xue W, Zender L, Magnus J, Ridzon D, et al: A microRNA component of the p53 tumour suppressor network. Nature 2007, 447(7148):1130-1134.

45. Zhang L, Volinia S, Bonome T, Calin GA, Greshock J, Yang N, Liu CG, Giannakakis A, Alexiou P, Hasegawa K, et al: Genomic and epigenetic alterations deregulate microRNA expression in human epithelial ovarian cancer. Proc Natl Acad Sci U S A 2008, 105(19):7004-7009.

46. Zhang L, Huang J, Yang N, Greshock J, Megraw MS, Giannakakis A, Liang S, Naylor TL, Barchetti A, Ward MR, et al: microRNAs exhibit high frequency genomic alterations in human cancer. Proc Natl Acad Sci U S A 2006, 103(24):9136-9141.

47. Nam EJ, Yoon H, Kim SW, Kim H, Kim YT, Kim JH, Kim JW, Kim S: MicroRNA expression profiles in serous ovarian carcinoma. Clin Cancer Res 2008, 14(9):2690-2695.

48. Dahiya N, Sherman-Baust CA, Wang TL, Davidson B, Shih le M, Zhang Y, Becker KG, Morin PJ, Wood W: MicroRNA expression and identification of putative miRNA targets in ovarian cancer. PLoS One 2008 3(6):e2436

49. Wyman SK, Parkin RK, Mitchell PS, Fritz BR, O'Briant K, Godwin AK, Urban N, Drescher CW, Knudsen BS, Tewari M: Repertoire of microRNAs in epithelial ovarian cancer as determined by next generation sequencing of small RNA cDNA libraries. PLoS One 2009, 4(4):e5311.

50. Lee CH, Subramanian S, Beck AH, Espinosa I, Senz J, Zhu SX, Huntsman D, van de Rijn M, Gilks CB: MicroRNA profiling of BRCA1/2 mutation-carrying 
and non-mutation-carrying high-grade serous carcinomas of ovary. PLoS One 2009, 4(10):e7314.

51. Yang H, Kong W, He L, Zhao JJ, O'Donnell JD, Wang J, Wenham RM, Coppola D, Kruk PA, Nicosia SV, et al: MicroRNA expression profiling in human ovarian cancer: miR-214 induces cell survival and cisplatin resistance by targeting PTEN. Cancer Res 2008, 68(2):425-433.

52. Korpal M, Lee ES, Hu G, Kang Y: The miR-200 family inhibits epithelialmesenchymal transition and cancer cell migration by direct targeting of E-cadherin transcriptional repressors ZEB1 and ZEB2. J Biol Chem 2008 , 283(22):14910-14914.

53. Huber MA, Kraut N, Beug H: Molecular requirements for epithelialmesenchymal transition during tumor progression. Curr Opin Cell Biol 2005, 17(5):548-558

54. Park SM, Gaur AB, Lengyel E, Peter ME: The miR-200 family determines the epithelial phenotype of cancer cells by targeting the E-cadherin repressors ZEB1 and ZEB2. Genes Dev 2008, 22(7):894-907.

55. Gregory PA, Bert AG, Paterson EL, Barry SC, Tsykin A, Farshid G, Vadas MA, Khew-Goodall Y, Goodall GJ: The miR-200 family and miR-205 regulate epithelial to mesenchymal transition by targeting ZEB1 and SIP1. Nat Cell Biol 2008, 10(5):593-601.

56. Gregory PA, Bracken CP, Bert AG, Goodall GJ: MicroRNAs as regulators of epithelial-mesenchymal transition. Cell Cycle 2008, 7(20):3112-3118.

57. Kong D, Li Y, Wang Z, Banerjee S, Ahmad A, Kim HR, Sarkar FH: miR-200 regulates PDGF-D-mediated epithelial-mesenchymal transition, adhesion, and invasion of prostate cancer cells. Stem Cells 2009, 27(8):1712-1721.

58. Imai T, Horiuchi A, Shiozawa T, Osada R, Kikuchi N, Ohira S, Oka K, Konishi I: Elevated expression of E-cadherin and alpha-, beta-, and gammacatenins in metastatic lesions compared with primary epithelial ovarian carcinomas. Hum Pathol 2004, 35(12):1469-1476.

59. Leskela S, Leandro-Garcia LJ, Mendiola M, Barriuso J, Inglada-Perez L, Munoz I, Martinez-Delgado B, Redondo A, de Santiago J, Robledo M, et al: The miR-200 family controls beta-tubulin III expression and is associated with paclitaxel-based treatment response and progression-free survival in ovarian cancer patients. Endocr Relat Cancer 2011, 18(1):85-95.

60. Rosell R, Scagliotti G, Danenberg KD, Lord RV, Bepler G, Novello S, Cooc J, Crino L, Sanchez JJ, Taron M, et al: Transcripts in pretreatment biopsies from a three-arm randomized trial in metastatic non-small-cell lung cancer. Oncogene 2003, 22(23):3548-3553.

61. Seve P, Mackey J, Isaac S, Tredan O, Souquet PJ, Perol M, Lai R, Voloch A, Dumontet C: Class III beta-tubulin expression in tumor cells predicts response and outcome in patients with non-small cell lung cancer receiving paclitaxel. Mol Cancer Ther 2005, 4(12):2001-2007.

62. Seve $P$, Dumontet $C$ : Is class III beta-tubulin a predictive factor in patients receiving tubulin-binding agents? Lancet Oncol 2008, 9(2):168-175.

63. Koh Y, Kim TM, Jeon YK, Kwon TK, Hah JH, Lee SH, Kim DW, Wu HG, Rhee CS, Sung MW, et al: Class III beta-tubulin, but not ERCC1, is a strong predictive and prognostic marker in locally advanced head and neck squamous cell carcinoma. Ann Oncol 2009, 20(8):1414-1419.

64. Ferrandina G, Zannoni GF, Martinelli E, Paglia A, Gallotta V, Mozzetti S, Scambia G, Ferlini C: Class III beta-tubulin overexpression is a marker of poor clinical outcome in advanced ovarian cancer patients. Clin Cancer Res 2006, 12(9):2774-2779.

65. Kavallaris M, Kuo DY, Burkhart CA, Regl DL, Norris MD, Haber M, Horwitz SB Taxol-resistant epithelial ovarian tumors are associated with altered expression of specific beta-tubulin isotypes. J Clin Invest 1997, 100(5):1282-1293.

66. Mozzetti S, Ferlini C, Concolino P, Filippetti F, Raspaglio G, Prislei S, Gallo D, Martinelli E, Ranelletti FO, Ferrandina G, et al: Class III beta-tubulin overexpression is a prominent mechanism of paclitaxel resistance in ovarian cancer patients. Clin Cancer Res 2005, 11(1):298-305.

67. Umezu T, Shibata K, Kajiyama H, Terauchi M, Ino K, Nawa A, Kikkawa F: Taxol resistance among the different histological subtypes of ovarian cancer may be associated with the expression of class III beta-tubulin. Int J Gynecol Pathol 2008, 27(2):207-212.

68. Roush S, Slack FJ: The let-7 family of microRNAs. Trends Cell Biol 2008 18(10):505-516.

69. Pasquinelli $A E$, Reinhart BJ, Slack F, Martindale MQ, Kuroda MI, Maller B, Hayward DC, Ball EE, Degnan B, Muller P, et al: Conservation of the sequence and temporal expression of let-7 heterochronic regulatory RNA. Nature 2000, 408(6808):86-89.
70. Takamizawa J, Konishi H, Yanagisawa K, Tomida S, Osada H, Endoh H, Harano T, Yatabe Y, Nagino M, Nimura Y, et al: Reduced expression of the let-7 microRNAs in human lung cancers in association with shortened postoperative survival. Cancer Res 2004, 64(11):3753-3756.

71. Yang N, Kaur S, Volinia S, Greshock J, Lassus H, Hasegawa K, Liang S, Leminen A, Deng S, Smith L, et al: MicroRNA microarray identifies Let-7i as a novel biomarker and therapeutic target in human epithelial ovarian cancer. Cancer Res 2008, 68(24):10307-10314.

72. Johnson SM, Grosshans H, Shingara J, Byrom M, Jarvis R, Cheng A, Labourier E, Reinert KL, Brown D, Slack FJ: RAS is regulated by the let-7 microRNA family. Cell 2005, 120(5):635-647.

73. Bussing I, Slack FJ, Grosshans H: let-7 microRNAs in development, stem cells and cancer. Trends Mol Med 2008, 14(9):400-409.

74. Johnson CD, Esquela-Kerscher A, Stefani G, Byrom M, Kelnar K, Ovcharenko D, Wilson M, Wang X, Shelton J, Shingara J, et al: The let-7 microRNA represses cell proliferation pathways in human cells. Cancer Res 2007, 67(16):7713-7722.

75. Schultz J, Lorenz P, Gross G, Ibrahim S, Kunz M: MicroRNA let-7b targets important cell cycle molecules in malignant melanoma cells and interferes with anchorage-independent growth. Cell Res 2008, 18(5):549-557

76. Wang Y, Hu X, Greshock J, Shen L, Yang X, Shao Z, Liang S, Tanyi JL, Sood AK, Zhang L: Genomic DNA Copy-Number Alterations of the let-7 Family in Human Cancers. PLoS One 2012, 7(9):e44399.

77. Chen GQ, Zhao ZW, Zhou HY, Liu YJ, Yang HJ: Systematic analysis of microRNA involved in resistance of the MCF-7 human breast cancer cell to doxorubicin. Med Oncol 2010, 27(2):406-415.

78. Blower PE, Chung JH, Verducci JS, Lin S, Park JK, Dai Z, Liu CG, Schmittgen TD, Reinhold WC, Croce CM, et al: MicroRNAs modulate the chemosensitivity of tumor cells. Mol Cancer Ther 2008, 7(1):1-9.

79. Weidhaas JB, Babar I, Nallur SM, Trang P, Roush S, Boehm M, Gillespie E, Slack FJ: MicroRNAs as potential agents to alter resistance to cytotoxic anticancer therapy. Cancer Res 2007, 67(23):11111-11116.

80. Boyerinas B, Park SM, Murmann AE, Gwin K, Montag AG, Zillhardt M, Hua YJ, Lengyel E, Peter ME: Let-7 modulates acquired resistance of ovarian cancer to Taxanes via IMP-1-mediated stabilization of multidrug resistance 1. Int J Cancer 2012, 130(8):1787-1797.

81. Lu L, Schwartz P, Scarampi L, Rutherford T, Canuto EM, Yu H, Katsaros D: MicroRNA let-7a: a potential marker for selection of paclitaxel in ovarian cancer management. Gynecol Oncol 2011, 122(2):366-371.

82. Corney DC, Hwang Cl, Matoso A, Vogt M, Flesken-Nikitin A, Godwin AK, Kamat AA, Sood AK, Ellenson LH, Hermeking $H$, et al: Frequent downregulation of miR-34 family in human ovarian cancers. Clin Cancer Res 2010, 16(4):1119-1128.

83. Nagaraja AK, Creighton CJ, Yu Z, Zhu H, Gunaratne PH, Reid JG, Olokpa E, Itamochi H, Ueno NT, Hawkins SM, et al: A link between mir-100 and FRAP1/mTOR in clear cell ovarian cancer. Mol Endocrinol 2010, 24(2):447-463

84. Peng DX, Luo M, Qiu LW, He YL, Wang XF: Prognostic implications of microRNA-100 and its functional roles in human epithelial ovarian cancer. Oncol Rep 2012, 27(4):1238-1244.

85. Mabuchi S, Kawase C, Altomare DA, Morishige K, Sawada K, Hayashi M Tsujimoto M, Yamoto M, Klein-Szanto AJ, Schilder RJ, et al: mTOR is a promising therapeutic target both in cisplatin-sensitive and cisplatinresistant clear cell carcinoma of the ovary. Clin Cancer Res 2009, 15(17):5404-5413.

86. Creighton CJ, Fountain MD, Yu Z, Nagaraja AK, Zhu H, Khan M, Olokpa E, Zariff A, Gunaratne PH, Matzuk MM, et al: Molecular profiling uncovers a p53-associated role for microRNA-31 in inhibiting the proliferation of serous ovarian carcinomas and other cancers. Cancer Res 2010 70(5):1906-1915

87. Ueda T, Volinia S, Okumura H, Shimizu M, Taccioli C, Rossi S, Alder H, Liu CG, Oue N, Yasui W, et al: Relation between microRNA expression and progression and prognosis of gastric cancer: a microRNA expression analysis. Lancet Oncol 2010, 11(2):136-146.

88. Penna E, Orso F, Cimino D, Tenaglia E, Lembo A, Quaglino E, Poliseno L, Haimovic A, Osella-Abate S, De Pitta C, et al: microRNA-214 contributes to melanoma tumour progression through suppression of TFAP2C. EMBO J 2011, 30(10):1990-2007.

89. Volinia S, Calin GA, Liu CG, Ambs S, Cimmino A, Petrocca F, Visone R, lorio $M$, Roldo $C$, Ferracin $M$, et al: A microRNA expression signature of human 
solid tumors defines cancer gene targets. Proc Natl Acad Sci U S A 2006, 103(7):2257-2261.

90. Blenkiron C, Goldstein LD, Thorne NP, Spiteri I, Chin SF, Dunning MJ, Barbosa-Morais NL, Teschendorff AE, Green AR, Ellis IO, et al: MicroRNA expression profiling of human breast cancer identifies new markers of tumor subtype. Genome Biol 2007, 8(10):R214.

91. Qiang R, Wang F, Shi LY, Liu M, Chen S, Wan HY, Li YX, Li X, Gao SY, Sun BC, et al: Plexin-B1 is a target of miR-214 in cervical cancer and promotes the growth and invasion of HeLa cells. Int J Biochem Cell Biol 2011, 43(4):632-641.

92. Testa JR, Bellacosa A: AKT plays a central role in tumorigenesis. Proc Natl Acad Sci U S A 2001, 98(20):10983-10985.

93. Yin G, Chen R, Alvero AB, Fu HH, Holmberg J, Glackin C, Rutherford T, Mor G: TWISTing stemness, inflammation and proliferation of epithelial ovarian cancer cells through MIR199A2/214. Oncogene 2010, 29(24):3545-3553.

94. Lee MS, Lowe GN, Strong DD, Wergedal JE, Glackin CA: TWIST, a basic helix-loop-helix transcription factor, can regulate the human osteogenic lineage. J Cell Biochem 1999, 75(4):566-577.

95. Lee MS, Lowe G, Flanagan S, Kuchler K, Glackin CA: Human Dermo-1 has attributes similar to twist in early bone development. Bone 2000, 27(5):591-602.

96. Bialek P, Kern B, Yang X, Schrock M, Sosic D, Hong N, Wu H, Yu K, Ornitz $\mathrm{DM}$, Olson EN, et al: $\mathrm{A}$ twist code determines the onset of osteoblast differentiation. Dev Cell 2004, 6(3):423-435.

97. Ota MS, Loebel DA, O'Rourke MP, Wong N, Tsoi B, Tam PP: Twist is required for patterning the cranial nerves and maintaining the viability of mesodermal cells. Dev Dyn 2004, 230(2):216-228.

98. Li Z, Lu J, Sun M, Mi S, Zhang H, Luo RT, Chen P, Wang Y, Yan M, Qian Z, et al: Distinct microRNA expression profiles in acute myeloid leukemia with common translocations. Proc Natl Acad Sci U S A 2008, 105(40):15535-15540.

99. Xu G, Zhong Y, Munir S, Yang BB, Tsang BK, Peng C: Nodal induces apoptosis and inhibits proliferation in human epithelial ovarian cancer cells via activin receptor-like kinase 7. J Clin Endocrinol Metab 2004, 89(11):5523-5534.

100. Li Y, Tan W, Neo TW, Aung MO, Wasser S, Lim SG, Tan TM: Role of the miR106b-25 microRNA cluster in hepatocellular carcinoma. Cancer Sci 2009, 100(7):1234-1242.

101. Fang L, Deng Z, Shatseva T, Yang J, Peng C, Du WW, Yee AJ, Ang LC, He C, Shan SW, et al: MicroRNA miR-93 promotes tumor growth and angiogenesis by targeting integrin-beta8. Oncogene 2011, 30(7):806-821.

102. Fu X, Tian J, Zhang L, Chen Y, Hao Q: Involvement of microRNA-93, a new regulator of PTEN/Akt signaling pathway, in regulation of chemotherapeutic drug cisplatin chemosensitivity in ovarian cancer cells. FEBS Lett 2012, 586(9):1279-1286.

103. Altomare DA, Wang HQ, Skele KL, De Rienzo A, Klein-Szanto AJ, Godwin AK, Testa JR: AKT and mTOR phosphorylation is frequently detected in ovarian cancer and can be targeted to disrupt ovarian tumor cell growth. Oncogene 2004, 23(34):5853-5857.

104. Si ML, Zhu S, Wu H, Lu Z, Wu F, Mo YY: miR-21-mediated tumor growth. Oncogene 2007, 26(19):2799-2803.

105. Slaby O, Svoboda M, Fabian P, Smerdova T, Knoflickova D, Bednarikova M, Nenutil R, Vyzula R: Altered expression of miR-21, miR-31, miR-143 and miR-145 is related to clinicopathologic features of colorectal cancer. Oncology 2007, 72(5-6):397-402.

106. Lou Y, Yang X, Wang F, Cui Z, Huang Y: MicroRNA-21 promotes the cell proliferation, invasion and migration abilities in ovarian epithelial carcinomas through inhibiting the expression of PTEN protein. Int J Mol Med 2010, 26(6):819-827.

107. Polytarchou C, lliopoulos D, Hatziapostolou M, Kottakis F, Maroulakou I, Struhl K, Tsichlis PN: Akt2 regulates all Akt isoforms and promotes resistance to hypoxia through induction of miR-21 upon oxygen deprivation. Cancer Res 2011, 71(13):4720-4731.

108. Li J, Liang S, Yu H, Zhang J, Ma D, Lu X: An inhibitory effect of miR-22 on cell migration and invasion in ovarian cancer. Gynecol Oncol 2010, 119(3):543-548.

109. Kim TH, Kim YK, Kwon Y, Heo JH, Kang H, Kim G, An HJ: Deregulation of miR-519a, 153, and 485-5p and its clinicopathological relevance in ovarian epithelial tumours. Histopathology 2010, 57(5):734-743.
110. Lu L, Katsaros D, de la Longrais IA, Sochirca O, Yu H: Hypermethylation of let-7a-3 in epithelial ovarian cancer is associated with low insulin-like growth factor-II expression and favorable prognosis. Cancer Res 2007, 67(21):10117-10122.

111. Hu X, Macdonald DM, Huettner PC, Feng Z, El Naqa IM, Schwarz JK, Mutch DG, Grigsby PW, Powell SN, Wang X: A miR-200 microRNA cluster as prognostic marker in advanced ovarian cancer. Gynecol Oncol 2009, 114(3):457-464.

112. Taylor DD, Gercel-Taylor C: MicroRNA signatures of tumor-derived exosomes as diagnostic biomarkers of ovarian cancer. Gynecol Oncol 2008, 110(1):13-21

113. Shell S, Park SM, Radjabi AR, Schickel R, Kistner EO, Jewell DA, Feig C, Lengyel E, Peter ME: Let-7 expression defines two differentiation stages of cancer. Proc Natl Acad Sci U S A 2007, 104(27):11400-11405.

114. Garzon R, Marcucci G, Croce CM: Targeting microRNAs in cancer: rationale, strategies and challenges. Nat Rev Drug Discov 2010, 9(10):775-789.

115. Lu Y, Xiao J, Lin H, Bai Y, Luo X, Wang Z, Yang B: A single anti-microRNA antisense oligodeoxyribonucleotide (AMO) targeting multiple microRNAs offers an improved approach for microRNA interference. Nucleic Acids Res 2009, 37(3):e24.

116. Trang P, Medina PP, Wiggins JF, Ruffino L, Kelnar K, Omotola M, Homer R, Brown D, Bader AG, Weidhaas JB, et al: Regression of murine lung tumors by the let-7 microRNA. Oncogene 2010, 29(11):1580-1587.

117. Trang P, Wiggins JF, Daige CL, Cho C, Omotola M, Brown D, Weidhaas JB, Bader AG, Slack FJ: Systemic delivery of tumor suppressor microRNA mimics using a neutral lipid emulsion inhibits lung tumors in mice. Mol Ther 2011, 19(6):1116-1122.

118. Pramanik D, Campbell NR, Karikari C, Chivukula R, Kent OA, Mendell JT, Maitra A: Restitution of tumor suppressor microRNAs using a systemic nanovector inhibits pancreatic cancer growth in mice. Mol Cancer Ther 2011, 10(8):1470-1480

119. Suzuki HI, Yamagata K, Sugimoto K, Iwamoto T, Kato S, Miyazono K: Modulation of microRNA processing by p53. Nature 2009, 460(7254):529-533.

120. Liu C, Kelnar K, Liu B, Chen X, Calhoun-Davis T, Li H, Patrawala L, Yan H, Jeter $C$, Honorio $S$, et al: The microRNA miR-34a inhibits prostate cancer stem cells and metastasis by directly repressing CD44. Nat Med 2011, 17(2):211-215

121. Melo S, Villanueva A, Moutinho C, Davalos V, Spizzo R, Ivan C, Rossi S, Setien F, Casanovas O, Simo-Riudalbas $L$, et al: Small molecule enoxacin is a cancer-specific growth inhibitor that acts by enhancing TAR RNAbinding protein 2-mediated microRNA processing. Proc Natl Acad Sci U S A 2011, 108(11):4394-4399.

122. Shan G, Li Y, Zhang J, Li W, Szulwach KE, Duan R, Faghihi MA, Khalil AM, Lu L, Paroo Z, et al: A small molecule enhances RNA interference and promotes microRNA processing. Nat Biotechnol 2008, 26(8):933-940.

123. Jeon HM, Sohn YW, Oh SY, Kim SH, Beck S, Kim S, Kim H: ID4 imparts chemoresistance and cancer stemness to glioma cells by derepressing miR-9*-mediated suppression of SOX2. Cancer Res 2011, 71(9):3410-3421.

124. Cittelly DM, Das PM, Salvo VA, Fonseca JP, Burow ME, Jones FE: Oncogenic HER2\{Delta\}16 suppresses miR-15a/16 and deregulates BCL-2 to promote endocrine resistance of breast tumors. Carcinogenesis 2010, 31(12):2049-2057.

125. Hwang JH, Voortman J, Giovannetti E, Steinberg SM, Leon LG, Kim YT, Funel N, Park JK, Kim MA, Kang GH, et al: Identification of microRNA-21 as a biomarker for chemoresistance and clinical outcome following adjuvant therapy in resectable pancreatic cancer. PLoS One 2010, 5(5):e10630.

doi:10.1186/1757-2215-5-44

Cite this article as: Zaman et al:: Current status and implications of microRNAs in ovarian cancer diagnosis and therapy. Journal of Ovarian Research 2012 5:44. 